\title{
Effect of surgical cleaning of the skin on the pathergy phenomenon in Behçet's syndrome
}

\author{
Division of \\ Rheumatology, \\ Department of \\ Internal Medicine, \\ Cerrahpaşa Medical \\ Faculty, \\ Istanbul, Turkey \\ I Fresko \\ $S$ Yurdakul \\ H Yazıcı \\ Department of Plastic \\ and Reconstructive \\ Surgery, \\ Cerrahpaşa Medical \\ Faculty, \\ Istanbul, Turkey \\ M Bayramiçli \\ Department of \\ Dermatology, \\ Cerrahpaşa Medical \\ Faculty, \\ Istanbul, Turkey \\ C Mat \\ Correspondence to: \\ Professor Hasan Yazıc1, \\ Safa Sok. 17/4, \\ Kadıköy, Istanbul, \\ Turkey 81310 . \\ Accepted for publication \\ 4 March 1993
}

\author{
Izzet Fresko, Hasan Yazıcı, Mehmet Bayramiçli, Sebahattin Yurdakul, Cem Mat
}

\begin{abstract}
Objectives-To assess the effect of surgical cleaning of the skin on the pathergy phenomenon in Behçet's syndrome. Methods-The pathergy phenomenon was assessed in 183 patients with Behçet's syndrome in a single blind study at 48 hours after a needle prick of the forearm skin, cleaned in the conventional way with alcohol, with $10 \%$ povidone iodine, with $100 \%$ chlorhexidine, and with a $4 \%$ aqueous solution of chlorhexidine.

Results-The surgical cleaning of the forearm with povidone iodine before the application of the needle prick reduced the prevalence of the pathergy reaction to $27 \%$ from $48 \%$ in the conventionally (by alcohol swab) cleaned forearm. Cleaning the forearm with $100 \%$ chlorhexidine reduced the prevalence of the pathergy to $36 \%$ from $59 \%$ in the conventionally cleaned forearm. No significant changes were observed with a $4 \%$ aqueous solution of chlorhexidine.

Conclusions-Surgical cleaning of the skin with disinfectants of various concentrations reduces the prevalence of a positive pathergy test in Behçet's syndrome. This implies that more than the disruption of the structural integrity of the dermis and epidermis is involved in the production of the pathergy phenomenon in Behçet's syndrome.
\end{abstract}

(Ann Rheum Dis 1993; 52: 619-620)

The pathergy reaction is a non-specific cutaneous hypersensitivity almost unique to Behçet's syndrome. ${ }^{1-3}$ It can occasionally be observed in normal subjects, however. ${ }^{45}$ The cause of the pathergy reaction is not known and its prevalence varies in different parts of the world. ${ }^{6} 7$ The pathergy reaction is induced by inserting a sterile needle into the alcohol cleaned forearm of a patient and observing the formation of a papule or pustule. ${ }^{8}$

The crucial point in understanding the pathergy reaction, we believe, is whether this sterile needle introduces any agent(s) into the epidermis or dermis when it penetrates the skin, or whether the reaction is produced solely by the mechanical disruption of epidermal or dermal components, or a combination of the two. Therefore we hypothesised that surgically cleaning the forearm before executing the pathergy reaction would decrease the skin response if the needle indeed introduced agent(s) on the skin into the epidermis and dermis. In a blind protocol we compared the pathergy reaction in the surgically cleaned forearms of patients with Behçet's syndrome with that in forearms of the same subjects which had been cleaned routinely with alcohol.

\section{Patients and methods}

Three groups of patients with Behçet's syndrome were studied. In each patient one forearm was cleaned in the conventional manner with an alcohol swab whereas the other forearm was cleaned for four minutes with: $10 \%$ povidone iodine (100\% Betadine) (group A) $100 \%$ chlorhexidine solution (100\% Savlon) (group B); and 4\% aqueous chlorhexidine solution (4\% Savlon) (group C). Group A consisted of 94 patients, group $B$ of 47 patients, and group C of 42 patients, all fulfilling the classification criteria for Behçet's syndrome. ${ }^{9}$

The pathergy reaction was induced at two sites a few centimetres apart on each forearm, as previously reported, ${ }^{8}$ using a 20 gauge disposable needle for each site. Sterile gloves were used when applying the test to the surgically cleaned site. Immediately after the puncture, all the puncture sites were covered by sterile pads which were removed at 24 hours. The pathergy reactions were read blindly at 48 hours by two independent observers as either negative, doubtful, or one plus (presence of a papule) or two plus (presence of a pustule) reaction.

Sign and $\chi^{2}$ tests were used for statistical analyses and $\kappa$ analysis was used to assess the interobserver variation.

\section{Results}

In expressing the results, the pathergy reaction for a forearm was considered negative only if both sites of pathergy on that forearm were read as negative. A positive pathergy for a forearm was either two positive sites on that forearm (a concordant positive) or a positive and a negative site (a discordant positive). The number of concordant positive readings for a forearm in the whole study was 89 for the first observer and 64 for the second observer, whereas the number of discordant positives was 77 for the two observers. There were only two cases of a two plus reaction among all of the observations which were considered as positive. The only doubtful observation was in a patient excluded from the study because of a haematoma.

The table shows an acceptable interobserver agreement. It also shows that povidone iodine and 100\% chlorhexidine significantly 
Pathergy reaction under different conditions

\begin{tabular}{|c|c|c|c|c|c|c|c|c|c|c|c|}
\hline \multicolumn{4}{|c|}{$\begin{array}{l}\text { Povidone iodine }(10 \%) * \\
(n=93)\end{array}$} & \multicolumn{4}{|c|}{$\begin{array}{l}\text { Chlorhexidine }(100 \%) \dagger \\
(n=47)\end{array}$} & \multicolumn{4}{|c|}{$\begin{array}{l}\text { Chlorhexidine (4\%) } \\
(n=42)\end{array}$} \\
\hline $\begin{array}{l}\text { Surgically } \\
\text { cleaned } \\
\text { forearm }\end{array}$ & $\begin{array}{l}\text { Conventionally } \\
\text { cleaned } \\
\text { forearm }\end{array}$ & $\begin{array}{l}\text { First } \\
\text { observer }\end{array}$ & $\begin{array}{l}\text { Second } \\
\text { observer }\end{array}$ & $\begin{array}{l}\text { Surgically } \\
\text { cleaned } \\
\text { forearm }\end{array}$ & $\begin{array}{l}\text { Conventionally } \\
\text { cleaned } \\
\text { forearm }\end{array}$ & $\begin{array}{l}\text { First } \\
\text { observer }\end{array}$ & $\begin{array}{l}\text { Second } \\
\text { observer }\end{array}$ & $\begin{array}{l}\text { Surgically } \\
\text { cleaned } \\
\text { forearm }\end{array}$ & $\begin{array}{l}\text { Conventionally } \\
\text { cleaned } \\
\text { forearm }\end{array}$ & $\begin{array}{l}\text { First } \\
\text { observer }\end{array}$ & $\begin{array}{l}\text { Second } \\
\text { observer }\end{array}$ \\
\hline- & + & 238 & 195 & - & + & $14 \pi$ & 135 & - & + & $5 \|$ & $9 \|$ \\
\hline+ & - & $3 \AA$ & $3 \delta$ & + & - & 39 & $1 \int^{8}$ & + & - & $2 \|$ & $3 \|$ \\
\hline+ & + & 22 & 22 & + & + & 14 & 14 & + & + & 22 & 11 \\
\hline- & - & 45 & 49 & - & - & 16 & 19 & - & - & 13 & 19 \\
\hline
\end{tabular}

${ }^{\star}$ Interobserver agreement, $89 \cdot 8 \%$; $\kappa$ value, $0 \cdot 74$. †Interobserver agreement, $88 \cdot 3 \%$; $\kappa$ value, $0 \cdot 743$. $\ddagger$ Interobserer agreement $79 \cdot 2 \% ; \kappa$ value, $0 \cdot 58$.

$\oint$ Significant at $\mathrm{p}=0 \cdot 01$. ๆSignificant at $\mathrm{p}=0 \cdot 05$. $\|$ Significant at $\mathrm{p}=0 \cdot 25$.

suppressed the pathergy reaction. This was not observed with the $4 \%$ aqueous solution of chlorhexidine.

It can also be deduced from the table that according to the first observer the surgical cleaning of the forearm reduced the pathergy reaction from 48 to $27 \%\left(\chi^{2}=8 \cdot 26 ; \mathrm{p}<0.001\right)$ in the povidone iodine group and from 59 to $36 \%\left(\chi^{2}=4.26 ; \mathrm{p}<0.05\right)$ in the $100 \%$ chlorhexidine group. No such changes were observed in the group treated with the $4 \%$ aqueous solution of chlorhexidine where a $64 \%$ prevalence in pathergy was observed in the conventionally cleaned forearms and $57 \%$ in the surgically cleaned sites. The reduction in the occurrence of the pathergy reaction in the surgically cleaned forearm, according to the assessment of the second observer, was essentially the same.

\section{Discussion}

Povidone iodine and chlorhexidine are commonly used by surgeons in skin sterilisation. We chose to remove the sterile pads after the initial 24 hours as it was likely that $(a)$ no outside agent could penetrate the wound after 24 hours because of the fibrin plug and $(b)$ possible maceration that could be caused by the continuous application of the pads for 48 hours might have negatively influenced the production of a positive pathergy reaction. The appropriateness of using a $\chi^{2}$ analysis on two separate arms of a single subject may be questioned. We thought this was justified because (a) a separate analysis was performed using the number of patients responding in a certain way as indicated in the table and (b) different treatments were applied to each forearm for an individual effect, making the possible objection about independent representation in a four by four contingency table less strong.

Our results show that there was a significant suppression of the pathergy reaction by surgical sterilisation. We believe this shows that factors other than the mechanical disruption of the structural integrity of the dermis and epidermis affect the production of the pathergy phenomenon in Behçet's syndrome. Whether surgical cleaning removes or lessens the number of microorganisms or amount of chemical material (i.e. sebum), or both, on the skin to produce the effect remains to be determined. It would have been more desirable if total sterilisation could have been achieved, though this is difficult. ${ }^{10}$ In addition, it will be interesting to compare the skin commensals and perhaps the quality and the amount of sebum $^{11}$ in patients from countries between which the prevalence of the pathergy reaction differs. ${ }^{67}$

We initially used povidone iodine in our study and observed the reported suppression; however, we chose to continue with chlorhexidine because during our work we learned that the iodine contained in povidone iodine might have immunosuppressive properties. ${ }^{12}$ We were not able to find any reference to such effects with chlorhexidine. It is not known why $100 \%$ chlorhexidine was more effective than the $4 \%$ aqueous solution of the same agent in decreasing the frequency of the pathergy response. Although this could have been due to an antiseptic effect of the $100 \%$ solution it might also be due to a more potent scrubbing effect in that a $100 \%$ solution of chlorhexidine is more viscous.

Finally, our data suggest that the specificity of the pathergy test should be redefined in healthy and diseased control subjects using the methods described in this paper. Meanwhile, until that information is available, we suggest continuing the pathergy testing in the conventional manner.

We thank Mrs Emine Öztürk for her secretarial assistance.

1 Sobel J D, Heim S, Shafrin A, Gellei B. Cutaneous hyperreactivity in Behçet's disease. Dermatologica 1973; 146: $350-6$.

2 Tüzün Y, Altaç $M$, Yazıcı $H$, et al. Nonspecific skin hyperreactivity in Behçet's disease. Haematologica (Pavia) 1980; 65: 395-8.

3 Gilhar A, Winterstein G, Turani H, Landau J, Etzioni A. Skin hyperreactivity response (pathergy) in Behçet's disease. F Am Acad Dermatol 1990; 21: 329-30.

4 Altaç M, Tüzün Y, Yurdakul S, Binyildiz P, Yazıcı H. The validity of the pathergy test (non-specific skin hyperreactivity) in Behçet's disease. A double blind study by 62: 158-9.

5 Dilşen N, Koniçe M, Aral O, Aykat O. Standardization and evaluation of skin pathergy test (SPT) in Behçet's disease (BD) and controls [abstract]. Proceedings of the Royal Society of Medicine International Conference on Behçet' Disease; 1985 Sep 5-6; London. 1985; abstr 42.

6 Davies P G, Fordham J N, Kirwan J R, Barnes C G, Dinning W J. The pathergy test and Behçet's syndrome in Britain. Ann Rheum Dis 1984; 43: 70-3.

7 Yazıc1 H, Chamberlain M A, Tüzün Y, Yurdakul S Müftüoglu A. A comparative study of the patherg reaction among Turkish and British patients with Behçet's disease. Ann Rheum Dis 1984; 43: 74-5.

8 Yazıc $\mathrm{H}$, Tüzün $\mathrm{Y}$, Tanman A B, et al. Male patients with Behçet's syndrome have stronger pathergy reactions. Clin Exp Rheumatol 1985; 3: 137-41.

9 International Study Group for Behçet's Disease. Criteria for diagnosis of Behçet's disease. Lancet 1990; 335:

10 Roth R R, James W D. Microbiology of the skin: resident flora, ecology, infection. ff Am Acad Dermatol 1989; 3 367-90.

11 Yazıcı H, Mat C, Deniz S, et al. Sebum production is increased in Behçet's syndrome and even more so in rheumatoid arthritis. Clin Exp Rheumatol 1987; 5: 371-4

12 Horio T, Imamura S, Danno K, et al. Potassium iodide in the treatment of erythema nodosum and nodula vasculitis. Arch Dermatol 1981; 117: 29-31. 